\title{
Trend Momentum II: Driving Forces of Low Volatility and Momentum
}

\author{
Wilhelm Berghorn ${ }^{1}$, Martin T. Schulz ${ }^{2}$, Markus Vogl ${ }^{2} \&$ Sascha Otto ${ }^{3}$ \\ ${ }^{1}$ Mandelbrot Asset Management GmbH, Erlangen, Germany \\ ${ }^{2}$ University of Applied Sciences, Aschaffenburg, Germany \\ ${ }^{3}$ Die Sparkasse Bremen AG, Bremen, Germany \\ Correspondance: Wilhelm Berghorn, Mandelbrot Asset Management GmbH, Erlangen, Germany.
}

Received: September 24, 2020

Accepted: November 4, 2020

Online Published: February 10, 2021

doi:10.5430/ijfr.v12n3p300

URL: https://doi.org/10.5430/ijfr.v12n3p300

\begin{abstract}
In discussions and critiques on the validity of the Efficient Market Hypothesis, there are two important research focuses: statistical analyses showing that the basic assumption of statistical independence in price series is violated and empirical findings that show that significant market anomalies exist. In this paper, we combine both viewpoints by analyzing two important mathematical factor anomalies: low volatility and momentum. By applying an explicit trend model, we show that both anomalies require trending. Additionally, we show that the trend model exhibits lognormal trend characteristics. Furthermore, the model allows us to describe how low volatility uses implicitly asymmetric trend characteristics while momentum directly exploits trends. Using Mandelbrot's model of fractional Brownian Motions, we can finally link statistical analyses (measuring the Hurst exponent and persistence in returns) to the empirically observed momentum factor. Experimentally, the Hurst exponent in itself allows for a momentum strategy, and can be utilized to significantly improve low volatility strategies. In contrast to Mandelbrot's approach, we offer a non-stationary view that allows us to describe both investment strategies using the trend model.
\end{abstract}

Keywords: momentum effect, low volatility effect, efficient market hypothesis, Mandelbrot, fractional Brownian motion

\section{Introduction}

\subsection{Overview}

Since the definition of the Efficient Market Hypothesis (EMH) in Fama (1970), there has been a lively discussion on the validity of the used assumptions. The critiques applied are broad, and one may group them into three categories.

1. The first category covers the field of behavioral finance where the papers of DeBondt and Thaler (1987), Kahneman (2011), Shiller (2003) and Thaler (2015) challenge the underlying assumption that investors operate rationally.

2. The second category covers mathematical critiques that in a broader sense challenge the statistical independence of asset prices, which is mandatory for the weak form of the EMH (Taylor (1962), Stevenson and Bear (1970), Lo and McKinley (1998) and Mandelbrot and Van Ness (1968)). Lo and McKinley (1998) and Mandelbrot and Van Ness (1968) show through an analysis of scaling properties of volatility that there must be some statistical dependence of asset returns from the past. From a theoretical point of view, the Fractional Brownian Motion enables an efficient way to test whether underlying data exhibit persistence in price data. However, Mandelbrot and Van Ness (1968) tied these theoretical findings to the so-called 'long term memory effect'. This was later criticized by Lo (1991) who showed that this effect is absent if data is corrected for serial correlation.

3. The third category includes empirical studies that directly challenge the EMH by revealing abnormal returns, e.g. due to the value and the size effect. Both play an important role in explanations of market returns as documented by Fama and French (1992), Fama and French (1996), and Fama and French (2008).

In the empirical work done so far, two factors are outstanding from a mathematical point of view: The low volatility effect and more importantly the momentum effect.

Low volatility was analyzed in the context of the Capital Asset Pricing Model (CAPM) by Black, Jensen and Scholes 
(1972) and was originally observed by Friend and Blume (1970). Later observations are given in Haugen and Heins (1975) and in Frazzini and Pedersen (2014).

Momentum in contrast has been studied more intensively, e.g. in Jegadeesh (1990), Jegadeesh and Titman (1993), Grinblatt, Titman and Wermers (1994), Chan, Jegadeesh and Lakonishok (1996), Carhart (1997), Rouwenhorst (1998), Liew and Vassalou (1999), Moskowitz and Grinblatt (1999), Schiereck, DeBondt and Weber (1999), Hong, Lim and Stein (2000), Lee and Swaminathan (2000), Grundy and Martin (2001), Jegadeesh and Titman (2001), Okunev and White (2003), Cooper, Gutierrez and Hameed (2004), Asness, Moskowitz and Pedersen (2013), George and Hwang (2004), Moskowitz, Ooi and Pedersen (2010), Bandarchuk and Hilscher (2012), Novy-Marx (2012), Jacobs and Weber (2013), or Daniel and Moskowitz (2016).

The low volatility factor is directly counterintuitive to the CAPM, as companies with less volatile or more stable returns are compensated with higher returns on a risk-adjusted basis. Regarding momentum, abnormal returns are not only much higher compared to those of low volatility but also show far more challenging implications to the EMH.

In our paper, we experimentally link the second and third categories of EMH critique and combine low volatility with momentum. From a theoretical point of view and using the framework introduced in Berghorn (2015) we show that a non-stationary view supports a good description of empirical findings observed in literature and allows us to understand low volatility and momentum in a mathematical sense.

In discussions on momentum, the term 'trending' is used quite often. In particular, Moskowitz, Ooi and Pedersen (2010) showed that serial correlations allow exploiting momentum in different asset classes. However, what is a trend? As summarized in Maass et al. (2003), this is a matter of definition and scale. To measure trends, one must define how trends should be measured (e.g., by using moving averages) and at which scale this should occur (e.g., by using an averaging window of 200 trading days). In this paper, we use the wavelet-based trend model introduced in Berghorn (2015), as it allows us to analyze movements in price data with the highest degree of precision with respect to the generalized Heisenberg Uncertainty Principle (Louis, Maaß and Rieder, 1994). Trends are distinguished in linear upward and downward trends (see note 1). The broadness of this analysis is determined by using wavelet scales.

Scale matters and especially in regard to financial data. This is one of the key findings given by Mandelbrot and Van Ness (1968). In the Fractional Brownian Motion model, the re-scaling of distributions is self-similar, which is also the case for the model used in our paper.

\subsection{Outline of Work}

In the following, we use the trend model introduced in Berghorn (2015) to describe the momentum effect. In particular, we show in section 3 that by using the last trend visible under this model (for a given scale) and by measuring the relevant trend drift, we are able to almost perfectly replicate classical momentum strategies. These findings are important as they enable us to investigate major characteristics of the trend model. In other words, it allows us to take a non-stationary (or trend-based) view of momentum. We show in section 4.1 that the model allows us to derive trend characteristics that most likely follow a lognormal distribution. This reflects the findings in Brenner and Maier-Paape (2016), who suppose that specific characteristics may stem from a limit process. Using the trend model, a statistical analysis shows that the lognormal hypothesis is almost never rejected for almost all assets and at nearly all scales.

By comparing the results to those of random walk based models, we see that our findings are not conclusive in a stronger sense. Moreover, we are able to reject the lognormal hypothesis for longer realizations of random walks.

In section 4.3, we use the Hurst exponent and repeat an experiment conducted by Lo (1991) where we remove trends from the data used. We can show that the momentum effect vanishes and that almost all assets have Hurst exponents less than 0.5, revealing one of the key findings in Mandelbrot and Van Ness (1968): There is no 'long term memory effect' in financial data, and the Hurst exponent measures the persistence of returns instead. After showing that the volatility of assets and the Hurst exponent are key drivers behind momentum strategies, we explicitly construct a momentum strategy based on Hurst exponents only. The results challenge the theory of Fama and May (1970), as high Hurst exponents signal statistical dependence that leads directly to a momentum strategy. From the wavelet-based trend model, we can derive characteristics of momentum and show, that even when low volatility is involved, the model supports almost perfect replication. As such, we find in section 5 that both market anomalies are connected, and exploit some sort of trending, though at different scales. In section 6, we see that momentum is an aggressive strategy when applied at small scales whereas low volatility exploits long movements and uses stability in returns at larger scales. From this point of view, we can derive an important application for utilizing Hurst exponents: 
The combination of low volatility and Hurst exponents, leads to an improved version of low volatility while maintaining defensive factor characteristics.

\section{Long Only Classical Momentum Revisited}

We revisit the classical momentum strategy (long only) by using a monthly rebalancing scheme, which includes two performance measurements. One is based on 12-month returns, and the second on 6-month returns to create a momentum ranking list for all assets. The scheme can be summarized as follows:

1. Calculate the historical 12-month (6-month) performance of each asset.

2. Rank assets according to their performance from high to low.

3. Switch (rebalance) the portfolio to the 100 assets with the best performance.

4. Subtract a transaction fee of $10 \mathrm{bp}$ from the portfolio volume.

The data basis of our analysis is the Bloomberg World Index as constituted in June 2017. As we focus on the characteristics of time series data, we do not compensate for any index changes. Additionally, we do not compare the momentum strategy to the Bloomberg World Index, but to a value weighted market proxy introduced in Berghorn (2015).

The index itself includes 5,000 assets from several developed countries, whereas we filter all assets with a price notation of below 0.01 at each month. We focus our analysis on the period of 2005 to 2016, affording 12 years of backtesting. Due to limited investability, we eliminate all assets from China to form a subset of 3,747 assets (Bloomberg World-Index Ex China).

\section{Trend Momentum Revisited}

In examining the wavelet-based trend model introduced in Berghorn (2015), we use a matching algorithm (see note 2) to identify wavelet scales that are similar to the momentum scheme. In particular, we do not rank assets by their performance over the past 12 or 6 months, but use the trend decomposition approach of Berghorn (2015). Therefore, we estimate the drift of the last trend segment visible at a given wavelet scale. For the mathematical definition, please refer to Berghorn and Otto (2017a).

Furthermore, we adpopt a matching algorithm similar to Hooke and Jeeves (1961) that selects an optimal wavelet scale such that the resulting cumulative performance chart is close to the performance chart of the classical scheme. Matching quality is measured by a correlation analysis on a daily basis.

As shown in table 1, we are able to replicate the classical momentum strategy by the wavelet-based trend decomposition scheme almost perfectly. For 12-month period returns, wavelet trends with scale 34 fit best, whereas for 6-month period returns a scale of 19 is optimal. In the experiment, we match the performance charts of traditional momentum strategies (using 12- and 6-month return periods as an evaluation criterion) to the wavelet-based scheme via an optimization procedure. For this scheme we use the trend model discussed in Berghorn (2015) and base the trend evaluation on the trend drift of the last visible trend at scales 34 and 19, respectively. The specific return and risk figures are summarised in Appendix A. 
Table 1. Classical momentum strategy vs. wavelet-based trend decomposition scheme

\begin{tabular}{lccccc}
\hline & $\begin{array}{c}\text { Market Proxy } \\
\text { (Average } \\
\text { Prices) }\end{array}$ & $\begin{array}{c}\text { Classic } \\
\text { Momentum } 12 \\
\text { M Period } \\
\text { Return }\end{array}$ & $\begin{array}{c}\text { Wavelet-Trend } \\
\text { Drift Scale 34 }\end{array}$ & $\begin{array}{c}\text { Classic } \\
\text { Momentum } \\
\text { 6 M Period } \\
\text { Return }\end{array}$ & $\begin{array}{c}\text { Wavelet-Trend } \\
\text { Drift Scale 19 }\end{array}$ \\
\hline Return (p.a.) & $6.91 \%$ & $20.82 \%$ & $21.95 \%$ & $24.15 \%$ & $27.50 \%$ \\
Excess Return (p.a.) & $14.98 \%$ & $15.08 \%$ & $15.75 \%$ & $15.94 \%$ & $16.19 \%$ \\
Volatility (p.a.) & 0.0276 & 0.0777 & 0.0780 & 0.0840 & 0.0929 \\
Risk Adjusted Return & $-58.21 \%$ & $-58.50 \%$ & $-56.51 \%$ & $-51.08 \%$ & $-51.84 \%$ \\
Maximal Drawdown & & $0.0581 \%$ & $0.0623 \%$ & $0.0688 \%$ & $0.0787 \%$ \\
Alpha & & 0.5609 & 0.5382 & 0.5522 & 0.5621 \\
Beta & & 4.6255 & 4.5853 & 5.0280 & 5.6715 \\
t-statistics Alpha & 41.3842 & 36.7435 & 37.4360 & 37.5542 \\
t-statistics Beta & 0.3106 & 0.2620 & 0.2693 & 0.2706 \\
R2 & & & & & $17.24 \%$ \\
\hline
\end{tabular}

The momentum strategy and the wavelet-based trend decomposition scheme show a correlation of higher than 99\% and reveal similar performance characteristics. Due to these similarities we conclude, that it seems to be possible to replicate the traditional momentum strategy by using the wavelet-based trend model.

\section{Distributions of Trend Characteristics}

In the following, we test the cohorts of assets constituting the Bloomberg World Index Ex China for lognormality in trend characteristics. Trend characteristics include trend drift, trend volatility, and trend size, i.e., the average logreturn, the standard deviation of logreturns and the size in (trading) days per trend segment (see note 3).

We can show, that the model allows us to derive trend characteristics that most likely follow a lognormal distribution for almost every case. This result reflects the key findings of Brenner and Maier-Paape (2016), claiming that lognormal distributions can stem from an unknown limit process.

\subsection{Lognormal Trend Characteristics}

As mentioned in Table 1 we use wavelet scales 19 and 34 to test whether the trends evaluated exhibit lognormal trend characteristics. All assets with more than 25 trends (upward and downward trends combined) are analysed. To avoid boundary effects, we remove the first and last trend. The decomposition of trends is carried out for 2001 to 2016. In table 2, we list the percentage of assets for which we fail to reject a lognormal distribution of the relevant trend characteristic. For that purpose, we optimize the goodness-of-fit of the lognormal distribution parameters using maximum-likelihood estimates for every individual wavelet scale (according to Cullen and Frey (1999)). We test the significance of our results at a significane level of 5\% with Kolmogorov-Smirnov (KS) assuming that trend characteristics originate from the lognormal distribution with the estimated mean and standard deviation.

One might hope that this approach is able to separate real data from random data unambiguously. However, this is not the case, as Table 2 shows. For the random walk pendants, we measure the drift and volatility of the time series and create a synthetic random walk for the same number of data points. For each realization of the modeled asset, a wavelet trend decomposition is being generated, whereas all trend realizations are then jointly tested for lognormality.

As summarized in Table 2, we are not able to reject the null hypothesis of lognormal distributed trend characteristics 
for the real-world data and single random walk realizations, but we can do so for the longer random walk processes.

Table 2. Failed to Reject (FTR) Null Hypothesis 'Lognormal distributed trend characteristics' at a significance level of $5 \%$

\begin{tabular}{|c|c|c|c|c|c|c|c|c|}
\hline & $\begin{array}{c}\text { Scale } 19 \\
\text { Real } \\
\text { World } \\
\text { Data }\end{array}$ & $\begin{array}{c}\text { Scale } 34 \\
\text { Real } \\
\text { World } \\
\text { Data }\end{array}$ & $\begin{array}{l}\text { Scale } 19 \\
\text { Random } \\
\text { Walk (1) }\end{array}$ & $\begin{array}{l}\text { Scale } 34 \\
\text { Random } \\
\text { Walk (1) }\end{array}$ & $\begin{array}{c}\text { Scale } 19 \\
\text { Random } \\
\text { Walk (100) }\end{array}$ & $\begin{array}{c}\text { Scale } 34 \\
\text { Random } \\
\text { Walk (100) }\end{array}$ & $\begin{array}{c}\text { Scale } 19 \\
\text { Random } \\
\text { Walk } \\
(1000)\end{array}$ & $\begin{array}{c}\text { Scale } 34 \\
\text { Random } \\
\text { Walk } \\
(1000)\end{array}$ \\
\hline Number Assets & $2,950.00$ & 602.00 & $2,779.00$ & 212.00 & $2,846.00$ & 602.00 & $2,846.00$ & 602.00 \\
\hline $\begin{array}{l}\text { Average Number } \\
\text { Trends }\end{array}$ & 40.43 & 26.88 & 41.90 & 27.03 & $4,169.62$ & $2,325.51$ & $41,697.59$ & $23,227.74$ \\
\hline $\begin{array}{ll}\text { Fraction } & \text { FTR } \\
\text { Trend Size } & \end{array}$ & $99.39 \%$ & $99.17 \%$ & $99.28 \%$ & $99.53 \%$ & $46.13 \%$ & $81.06 \%$ & $0.00 \%$ & $0.00 \%$ \\
\hline $\begin{array}{ll}\text { Fraction } & \text { FTR } \\
\text { Trend Drift } & \end{array}$ & $98.85 \%$ & $99.34 \%$ & $98.74 \%$ & $98.11 \%$ & $16.97 \%$ & $46.84 \%$ & $0.00 \%$ & $0.00 \%$ \\
\hline $\begin{array}{l}\text { Fraction FTR } \\
\text { Trend Volatility }\end{array}$ & $98.20 \%$ & $99.00 \%$ & $98.16 \%$ & $97.17 \%$ & $0.00 \%$ & $2.99 \%$ & $0.00 \%$ & $0.00 \%$ \\
\hline $\begin{array}{l}\text { Fraction FTR } \\
\text { Absolute Return }\end{array}$ & $98.14 \%$ & $98.17 \%$ & $96.51 \%$ & $99.06 \%$ & $0.00 \%$ & $0.00 \%$ & $0.00 \%$ & $0.00 \%$ \\
\hline
\end{tabular}

By considering 100 random walk realizations, the null hypothesis of trend sizes following a lognormal distribution can be rejected for over 50\% of the cases. For all the other trend characteristics such as trend drift, trend volatility, and the absolute return of trends, the results are even stronger. When we extend the experiment to 1,000 realizations, the null hypothesis can be rejected in all cases. These results are consistent with the experiments published by Berghorn (2015), showing that Monte Carlo simulations using a random walk model do not verify the existence of a momentum effect. Furthermore, extremely long trends of asset data cannot be replicated by random walks.

Is the lognormality of trend characteristics thus the key driver of momentum? As shown in table 2 the real word data are relatively short compared to the random walk realizations. Furthermore, there are similar characteristics between the test scheme and the short random walk processes. Therefore, such a conclusion is not possible.

\subsection{Volatility and the Hurst Exponent as Drivers of Momentum}

One of the major accomplishments of Mandelbrot is the introduction of the Hurst exponent. In chaos theory and/or fractal geometry this exponent is understood as a roughness coefficient, e.g. for fractal surfaces. Having times series (such as financial price series) this exponent can be understood as a characteristic to describe "trending“ (Hurst exponent > 0.5) and „mean reversion“ (Hurst exponent $<0.5$ ). An exponent of 0.5 in contrast is signalling statistical independence, which is a basic assumption of the EMH.

To identify the key drivers of momentum, we rather need a deeper statistical view, based on an estimation of Hurst exponents and the so-called rescaled range $(\mathrm{R} / \mathrm{S})$ - analysis (introduced by Mandelbrot) used in, e.g. Berghorn and Otto (2017a). According to this approach, we can show that almost every asset of the Bloomberg World Ex China Index has a Hurst exponent of greater than 0.5 (see Appendix B).

In our experimental approach, we first measure the volatilities of all assets and split the market into the $50 \%$ most volatile assets and the 50\% least volatile assets. Secondly, we estimate the Hurst exponents through an R/S - analysis and divide the market in the same way. Eventually, we repeat our original analysis with the seperated data sets and compare the momentum strategies (based on 6-month period returns) of all sub-markets. By comparing the used risk/return characteristics, it is evident that volatilities as well as Hurst exponents seem to be key drivers of the momentum effect (Table 3). This can be derived by comparing the risk adjusted return characteristics below. The 
cohort of high volatility stocks (in combination with momentum) yields almost twice of the risk adjusted returns if compared to to the cohort of low volatility stocks. The same conclusion can be drawn for cohorts of assets with higher Hurst exponents and lower Hurst exponents (where the conclusion is even stronger):

Table 3. Bloomberg World Index Ex China - 100 Assets - Cohorts

\begin{tabular}{|c|c|c|c|c|}
\hline & $\begin{array}{c}\text { Classic } \\
\text { Momentum } \\
\text { 6M Upper Half } \\
\text { Volatility }\end{array}$ & $\begin{array}{c}\text { Classic } \\
\text { Momentum } \\
\text { 6M Lower } \\
\text { Half Volatility }\end{array}$ & $\begin{array}{c}\text { Classic } \\
\text { Momentum 6M } \\
\text { Upper Half } \\
\text { Hurst Exponent }\end{array}$ & $\begin{array}{c}\text { Classic } \\
\text { Momentum 6M } \\
\text { Lower Half Hurst } \\
\text { Exponent }\end{array}$ \\
\hline Return Averaged Index (p.a.) & $8.39 \%$ & $5.02 \%$ & $8.10 \%$ & $5.74 \%$ \\
\hline Return Factor Momentum (p.a.) & $26.06 \%$ & $9.73 \%$ & $27.60 \%$ & $8.59 \%$ \\
\hline Excess Return (p.a.) & $17.67 \%$ & $4.71 \%$ & $19.50 \%$ & $2.86 \%$ \\
\hline Volatility Averaged Index (p.a.) & $18.68 \%$ & $13.65 \%$ & $16.95 \%$ & $14.46 \%$ \\
\hline Volatility Factor Momentum (p.a.) & $16.78 \%$ & $11.79 \%$ & $15.60 \%$ & $14.43 \%$ \\
\hline Risk Adjusted Return Averaged Index & 0.0267 & 0.0222 & 0.0285 & 0.0239 \\
\hline $\begin{array}{l}\text { Risk Adjusted } \text { Return } \text { Factor } \\
\text { Momentum }\end{array}$ & 0.0854 & 0.0487 & 0.0967 & 0.0354 \\
\hline Maximal Drawdown Averaged Index & $-65.51 \%$ & $-50.27 \%$ & $-65.62 \%$ & $-48.25 \%$ \\
\hline $\begin{array}{lll}\text { Maximal } & \text { Drawdown } & \text { Factor } \\
\text { Momentum } & & \end{array}$ & $-53.00 \%$ & $-39.83 \%$ & $-52.33 \%$ & $-43.87 \%$ \\
\hline Alpha & $0.0747 \%$ & $0.0278 \%$ & $0.0786 \%$ & $0.0212 \%$ \\
\hline Beta & 0.4565 & 0.4152 & 0.4951 & 0.4882 \\
\hline t-statistics Alpha & 5.1443 & 2.6732 & 5.9516 & 1.6733 \\
\hline t-statistics Beta & 36.3741 & 33.7492 & 39.3318 & 34.5566 \\
\hline R2 & 0.2582 & 0.2308 & 0.2895 & 0.2391 \\
\hline
\end{tabular}

As shown in Berghorn and Otto (2017a), the momentum effect can be mimicked by Monte Carlo simulations using Fractional Brownian Motions based on the Hurst exponent. This leads us to the assumption that Hurst exponents measure trending effects rather than long-term memory as mentioned by Mandelbrot and Van Ness (1968).

\subsection{Hurst Exponent and Trends}

According to Lo (1991) we analyze the effect of trends on the R/S-approach and show, how trends affect the momentum strategy. To verify that both are impacted once trends are eliminated, we use a 'detrending' scheme as follows.

First, we calculate linear up and down trend segments for each asset as modeled by the wavelet-based trend decomposition. Therefore we use scale 19 derived from the matching algorithm. Then we subtract logreturns of the linear trend model from logreturns of the original data series.

After removing trends from the data, almost all assets from the Bloomberg World Ex China Index exhibit Hurst exponents of less than 0.5 (see Appendix C). Thus, the persistence in returns measured from the Hurst exponent is 
almost non-existent after detrending the price data.

Furthermore, the cohort of detrended assets at a scale of 19 does not allow for any form of momentum. By applying a momentum strategy based on 6-month returns as a selection criterion, we can verify considerable underperformance, as Table 4 shows (see Note 4 ).

Table 4. Classic Momentum Factor Period Returns with 100 Assets (2005-2016, 12 yrs) - Detrended Scale 19

\begin{tabular}{|c|c|c|}
\hline & $\begin{array}{l}\text { World Index Ex China } \\
\text { Detrended Proxy }\end{array}$ & Momentum 6M 100 Assets \\
\hline Return (p.a.) & $0.31 \%$ & $-27.65 \%$ \\
\hline Excess Return (p.a.) & & $-27.96 \%$ \\
\hline Volatility (p.a.) & $15.81 \%$ & $18.01 \%$ \\
\hline Risk Adjusted Return & 0.0012 & -0.1113 \\
\hline Maximal Drawdown & $-31.03 \%$ & $-99.13 \%$ \\
\hline Alpha & & $-0.1247 \%$ \\
\hline Beta & & 0.5602 \\
\hline t-statistics Alpha & & -7.9254 \\
\hline t-statistics Beta & & 34.8385 \\
\hline R2 & & 0.2420 \\
\hline
\end{tabular}

These experiments reveal a key misconception made by Mandelbrot and Van Ness (1968). According to Lo (1991), there is no long-term memory concerning price data. In fact, the Hurst exponent is directly tied to trending.

\subsection{Hurst Exponent and a Factor Strategy}

In the following, we show through experiments that the Hurst exponent is well suited to improve well known factors such as low volatility. Moreover, it is closely related to momentum itself.

In Table 5, we summarize results derived from various ranking schemes based on a three-year observation period. As stated in chapter 2, we run factor strategies on 100 assets of the Bloomberg World Index Ex China. The selection of assets is conducted on a monthly ranking scheme based on the Hurst exponent, the inverse of the Hurst exponent, the volatility, the inverse of the volatility, and the Hurst exponent divided by volatility. These experiments shall demonstrate how the concept of volatility as an indicator for risk may be affected by the concept of "trending" and „mean reversion“ (measured by the Hurst exponent). Table 5 shows that the Hurst exponent represents a momentum strategy comparable (on a risk-adjusted basis) to that of a 12-month period return momentum factor (table 1). More importantly, the low volatility factor can be significantly improved on a risk adjusted basis when Hurst exponents are used for ranking. Finally, we can verify higher returns with slightly lower levels of volatility and lower maximal drawdowns. According to the last column of table 5 we can improve the results even further by using a z-scoring procedure for the ranking process. 
Table 5. Factor Analysis with 100 Assets

\begin{tabular}{lccccccc}
\hline & $\begin{array}{c}\text { Market } \\
\text { Proxy }\end{array}$ & $\begin{array}{c}\text { Hurst } \\
\text { Exponent }\end{array}$ & $1 /$ Hurst & Volatility & $1 /$ Volatility & $\begin{array}{c}\text { Hurst / } \\
\text { Volatility }\end{array}$ & $\begin{array}{c}\text { Z-Score } \\
\text { Hurst / } \\
\text { Volatility }\end{array}$ \\
\hline Return (p.a.) & $6.91 \%$ & $17.70 \%$ & $6.34 \%$ & $26.63 \%$ & $3.50 \%$ & $5.27 \%$ & $9.26 \%$ \\
Excess Return (p.a.) & & $10.79 \%$ & $-0.56 \%$ & $19.72 \%$ & $-3.40 \%$ & $-1.64 \%$ & $2.36 \%$ \\
Volatility (p.a.) & $14.98 \%$ & $13.04 \%$ & $10.81 \%$ & $20.65 \%$ & $7.63 \%$ & $7.42 \%$ & $8.27 \%$ \\
Risk Adjusted Return & 0.0276 & 0.0774 & 0.0352 & 0.0708 & 0.0279 & 0.0429 & 0.0663 \\
Maximal Drawdown & $-58.21 \%$ & $-54.38 \%$ & $-48.66 \%$ & $-65.95 \%$ & $-36.30 \%$ & $-35.52 \%$ & $-37.19 \%$ \\
Alpha & & $0.0489 \%$ & $0.0151 \%$ & $0.0781 \%$ & $0.0080 \%$ & $0.0139 \%$ & $0.0262 \%$ \\
Beta & & 0.529535 & 0.331628 & 0.483075 & 0.203885 & 0.227836 & 0.3039 \\
t-statistics Alpha & & 4.7068 & 1.5650 & 4.0226 & 1.1357 & 2.0949 & 3.7729 \\
t-statistics Beta & & 47.2754 & 31.9039 & 23.0692 & 26.9121 & 31.9498 & 40.6263 \\
R2 & & 0.3702 & 0.2112 & 0.1228 & 0.1600 & 0.2117 & 0.3027 \\
\hline
\end{tabular}

\section{Trends Revisited}

In the following, we broaden the trend analysis published in Berghorn (2015) on the Bloomberg World Index Ex China and divide all assets into trends parametrized by a given scale. For scales 2 to 128, we report different trend characteristics of upward and downward trends (see figures 1, 2 and 3). In particular, we measure the average trend size (separated by upward and downward trends) and average trend drifts (separated accordingly) (see note 3). The figures show structural differences between upward and downward movements:

- The average absolute trend drift is significantly higher for downward trends (from scale 9 onwards).

- The trend sizes observed are for downward trends on average shorter compared to upward trends, whereas the gap scales with the resolution of the analysis.

- The volatility is structurally stronger for downward trends (from scale 8 onwards).

Therefore, we can conclude, that downward trends involve faster, steeper and more volatile movements than upward trends. As such, it is clear that low volatility strategies rank assets that exhibit longer (and more stable) trends higher. 
Average Trend Drifts Bloomberg World Ex China

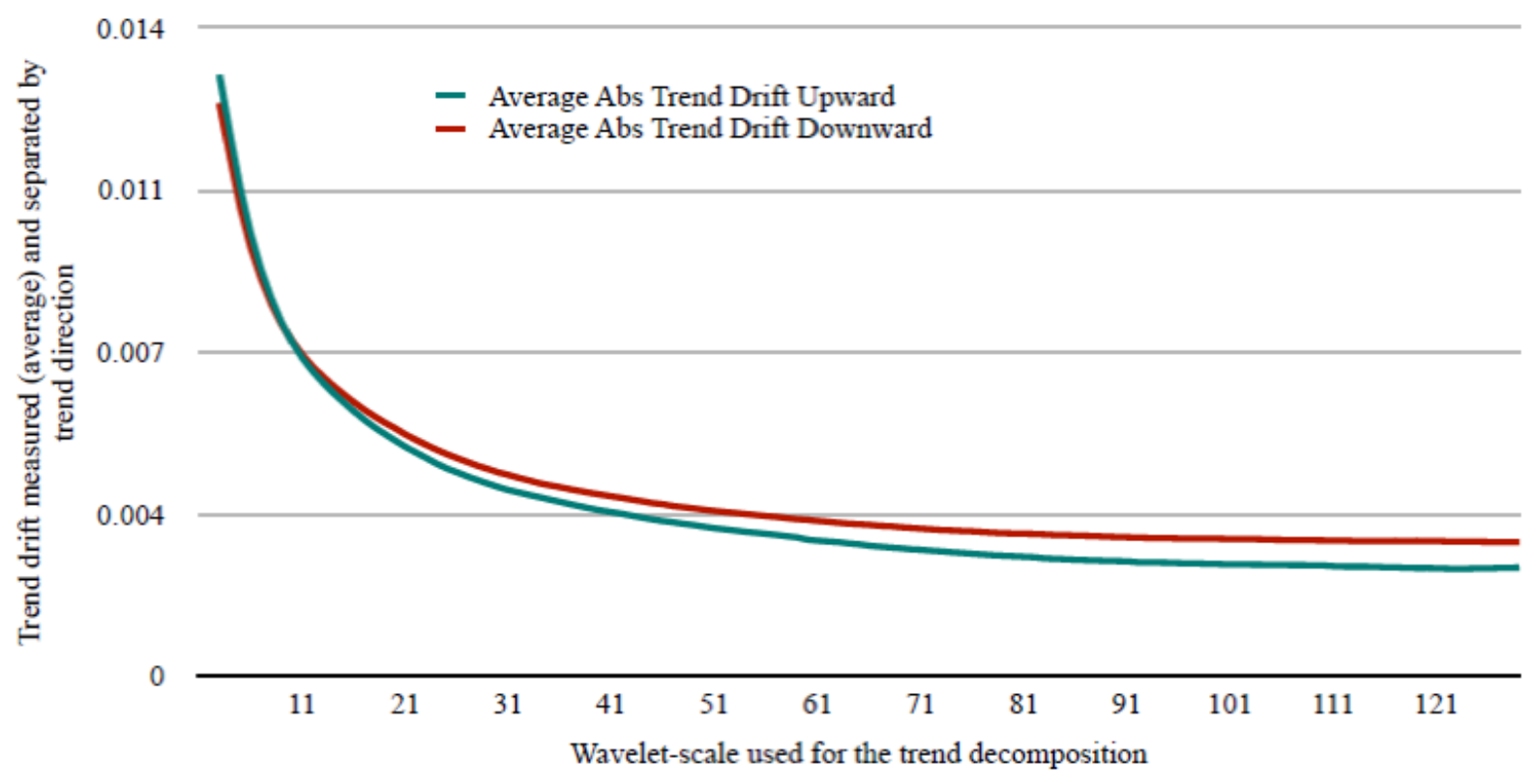

Figure 1. Average Trend Drifts Bloomberg World Index Ex China

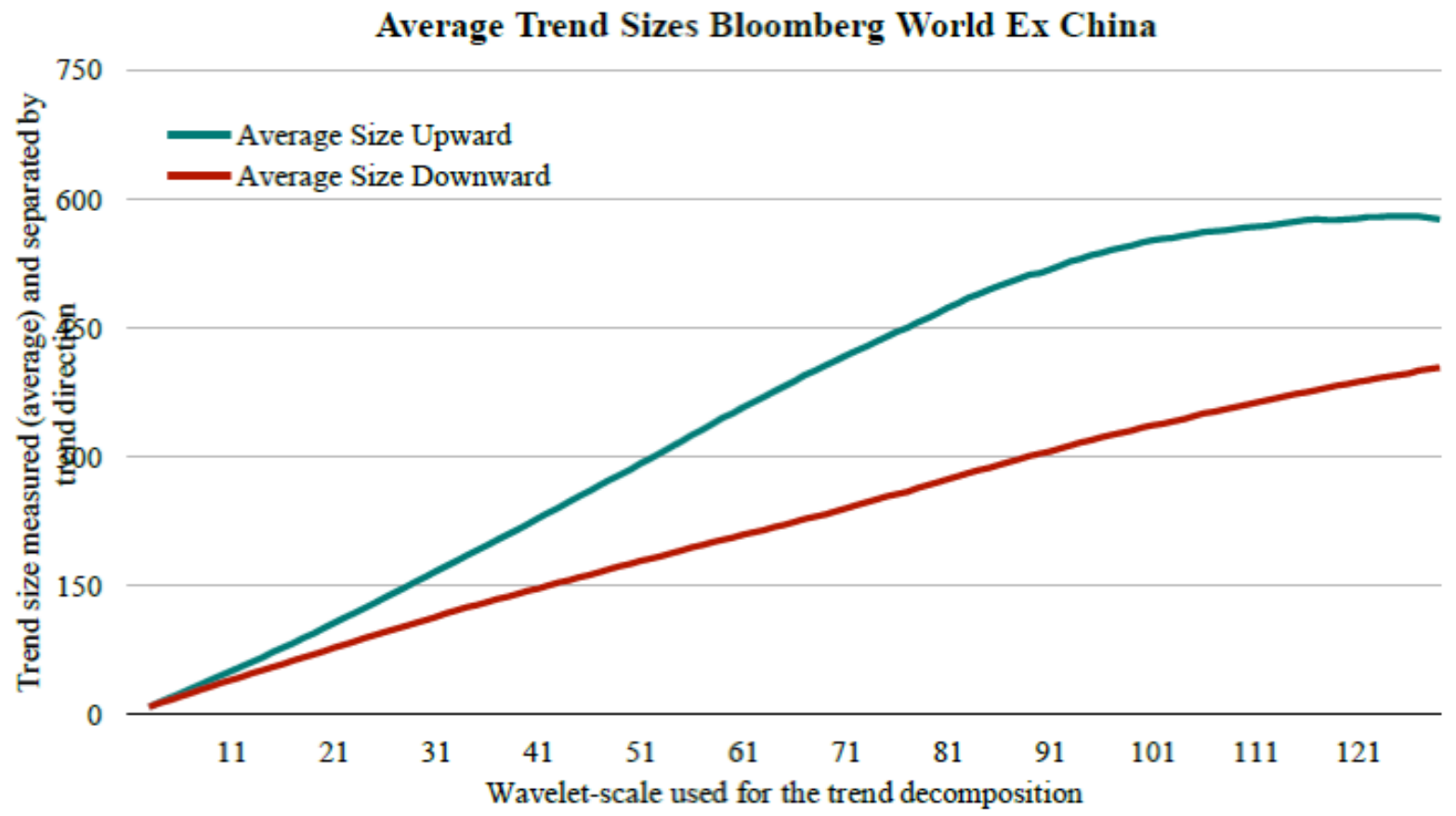

Figure 2. Average Trend Sizes Bloomberg World Index Ex China 


\section{Average Trend Volatilities Bloomberg World Ex China}

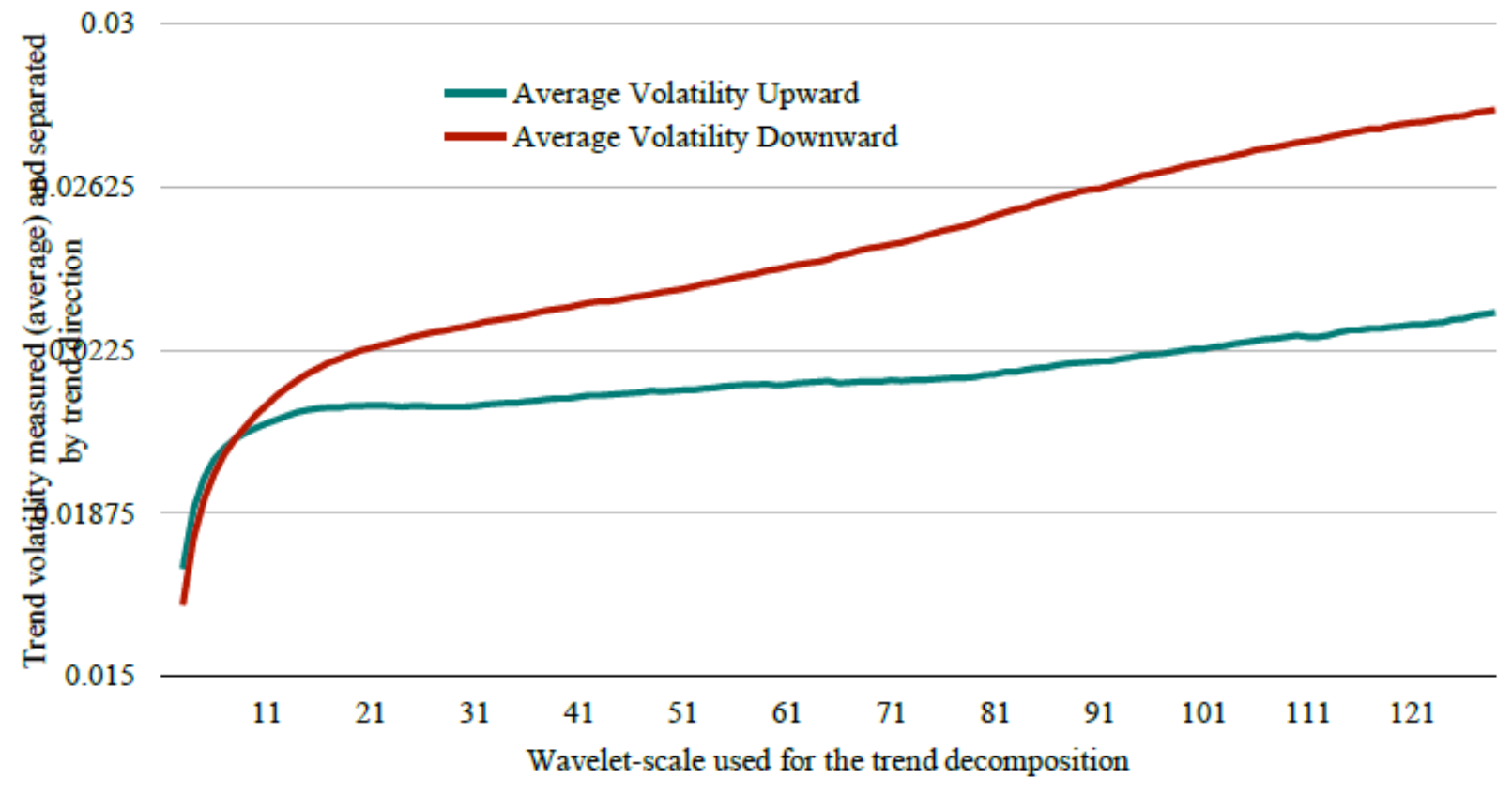

Figure 3. Average Trend Volatilities Bloomberg World Index Ex China

In the following experiment, we use the matching scheme introduced in chapter 2 to show that low volatility strategies (which typically rank assets according to the inverse volatility estimate based on the past 3 years of logreturn realizations) can be replicated by using a wavelet-based trend model approach. In contrast to the replication of momentum strategies, we use the volatility estimator of the last visible trend observed to reconcile for stability characteristics used by low volatility strategies.

As shown in Table 6, the wavelet-based trend model approach is able to replicate the performance figures of the low volatility anomaly. While the resulting factor strategy generates slightly lower return expectations, this is compensated by lower volatility levels and more importantly by a lower maximal drawdown. The correlation between the performance charts is round about $99.5 \%$. In particular, the matching algorithm generates a wavelet scale of 52 , which is much longer than those used for momentum strategies.

Table 6. Volatility Anomaly (3 Years) with 100 Assets (2005-2016, 12 yrs) - Bloomberg World Ex China

\begin{tabular}{lccc}
\hline & Market Proxy & $1 /$ Volatility & $\begin{array}{c}\text { Trend 1/Volatility } \\
\text { Scale 52 }\end{array}$ \\
\hline Return (p.a.) & $6.91 \%$ & $3.50 \%$ & $3.20 \%$ \\
Excess Return (p.a.) & & $-3.40 \%$ & $-3.71 \%$ \\
Volatility (p.a.) & $14.98 \%$ & $7.63 \%$ & $7.25 \%$ \\
Risk Adjusted Return & 0.0276 & 0.0279 & 0.0269 \\
Maximal Drawdown & $-58.21 \%$ & $-36.30 \%$ & $-32.97 \%$ \\
Alpha & & $0.0080 \%$ & $0.0068 \%$ \\
Beta & & 0.203885 & 0.207591
\end{tabular}



t-statistics Alpha
1.1357
1.0281
t-statistics Beta
26.9121
29.2608
R2
0.1600
0.1838

\section{Low Volatility and Momentum - Two Sides of One Medal}

As discussed in sections 3,4 and 5, there are strong assumptions, that the low volatility anomaly as well as momentum use the same underlying force, which we model directly using the wavelet-based trend model.

\subsection{Momentum Characteristics (Momentum at Scale 19)}

For the following set of experiments, we observe the momentum portfolio and calculate average monthly Hurst exponents, volatilities and maximum visible scales. The analysis is based on a momentum portfolio with trend drift at scale 19 replicating a 6-month period return momentum strategy.

We can immediately verify that momentum portfolios can be characterized as having higher Hurst exponents than the market average in almost every case (see figure 4). This implies that the momentum portfolio exhibits more persistence in returns. At the same time, the concentrated momentum portfolio resembles assets with stronger fluctuations and is thus characterized by higher levels of volatility relative to those of the market (see Figure 5). For trends that are leveraged, the entry level at scale 19 covers also trends observed at higher scales (see Figure 6).

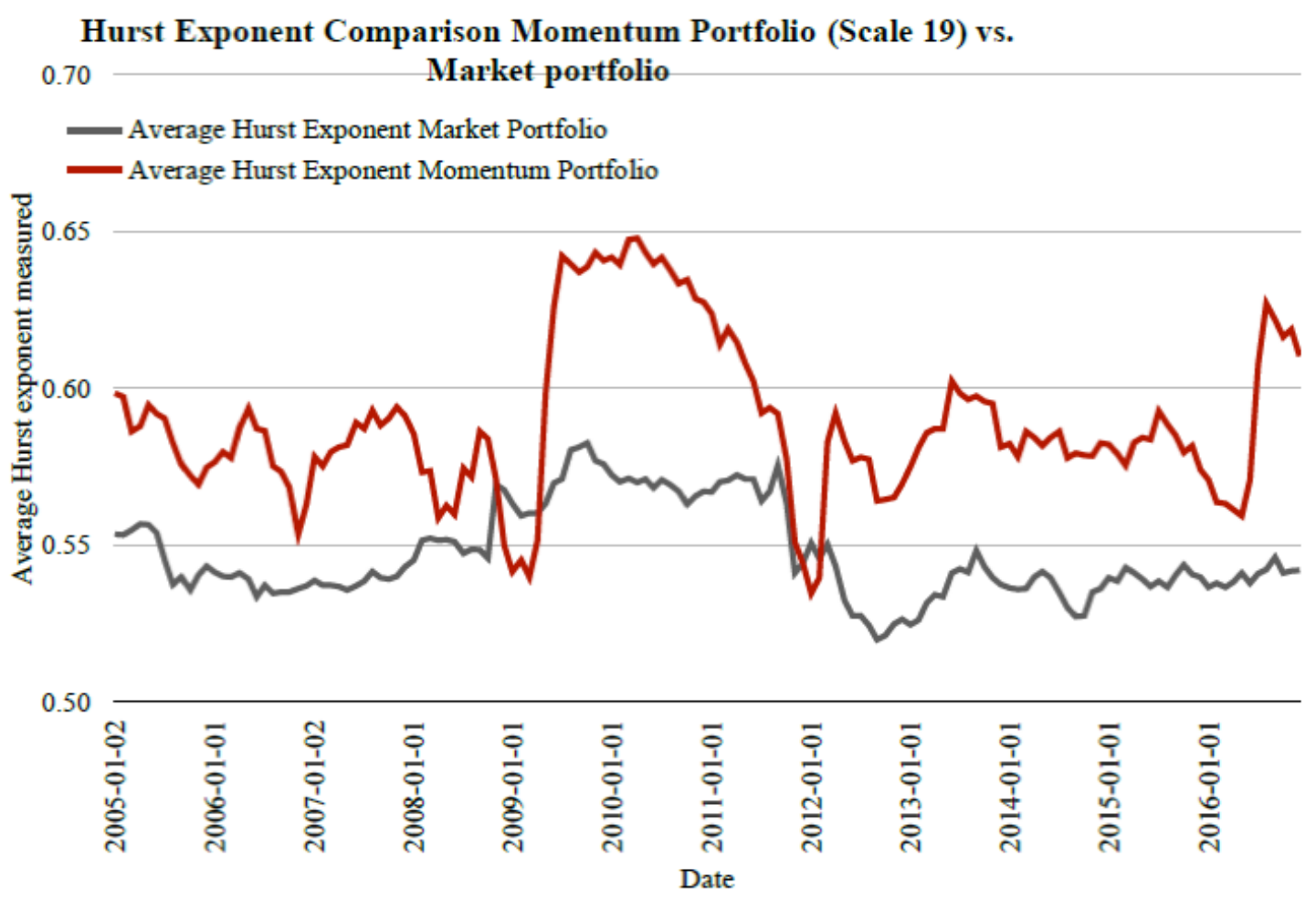

Figure 4. Hurst Exponent Comparison: Momentum Portfolio (Scale 19) vs. Market portfolio 
Volatility Comparison Momentum Portfolio (Scale 19) vs. Market Portfolio

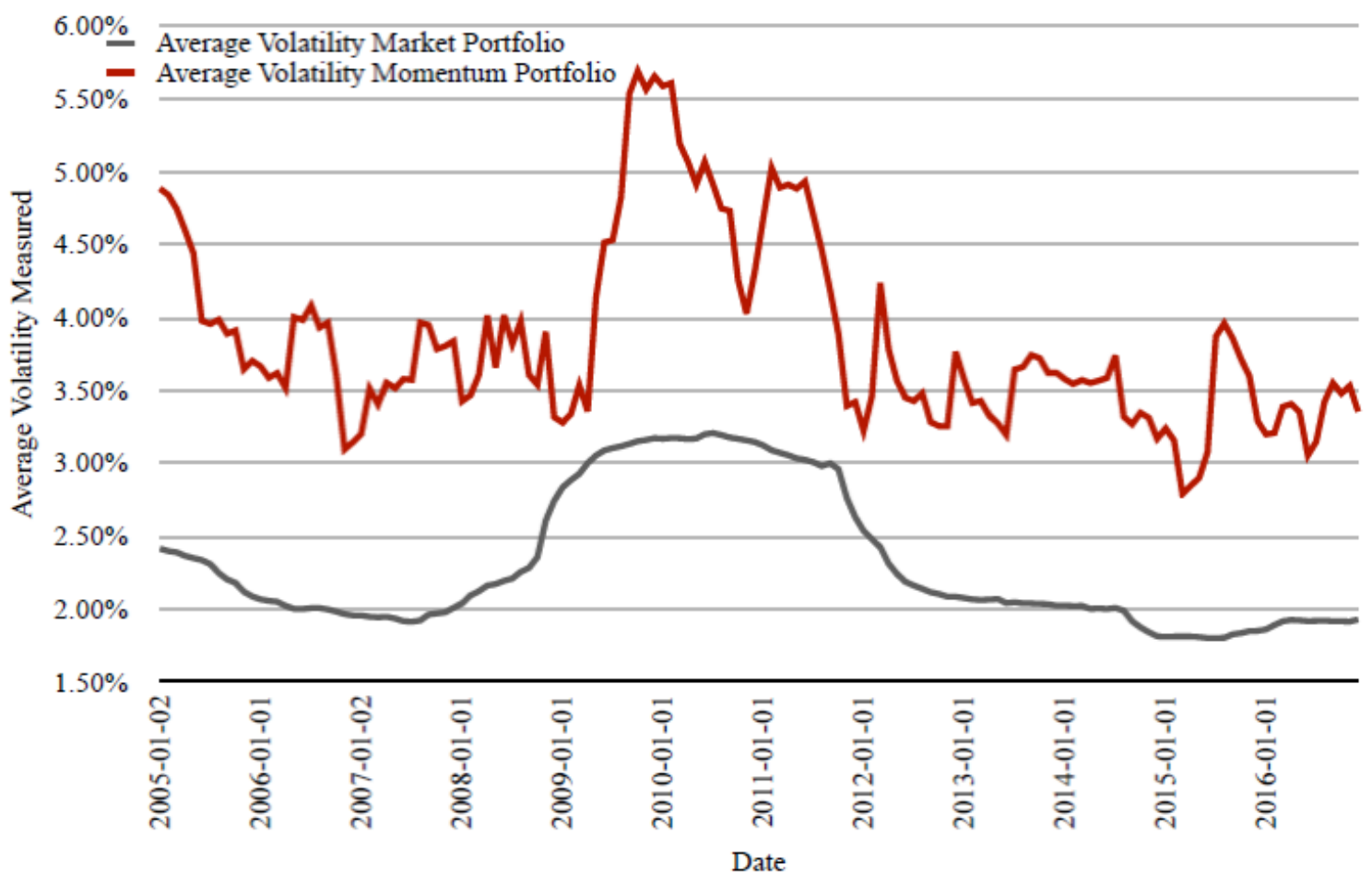

Figure 5. Volatility Comparison: Momentum Portfolio (Scale 19) vs. Market Portfolio

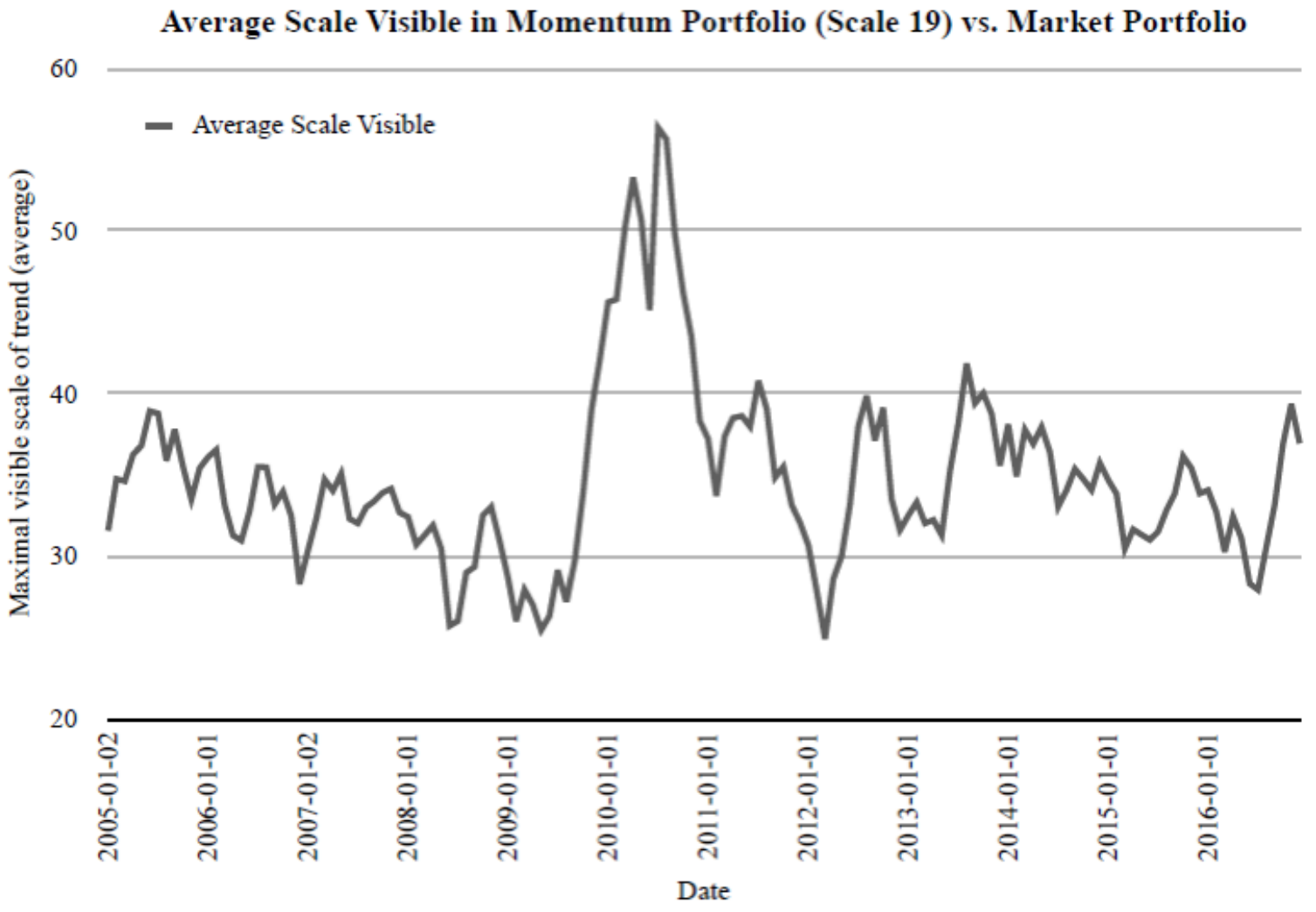

Figure 6. Average Scale Visible in Momentum Portfolio (Scale 19) 


\subsection{Low Volatility as Momentum at Scale 52 (Trend Volatility)}

In Figures 7, 8 and 9 we repeat our measurements from section 6.1 based on the low volatility anomaly replicated by the wavelet-based trend model. We focus on a trend portfolio with trend volatility at scale 52 replicating 36-month volatility estimates.

Figure 7 shows that the Hurst exponent is lower than the market average in almost every case. However, it still exhibits persistence in returns, as the exponents are still at a level above 0.5. By design, volatility levels are structurally lower and the trends used are much longer compared to those of lower scale momentum (see figures 8 and 9).

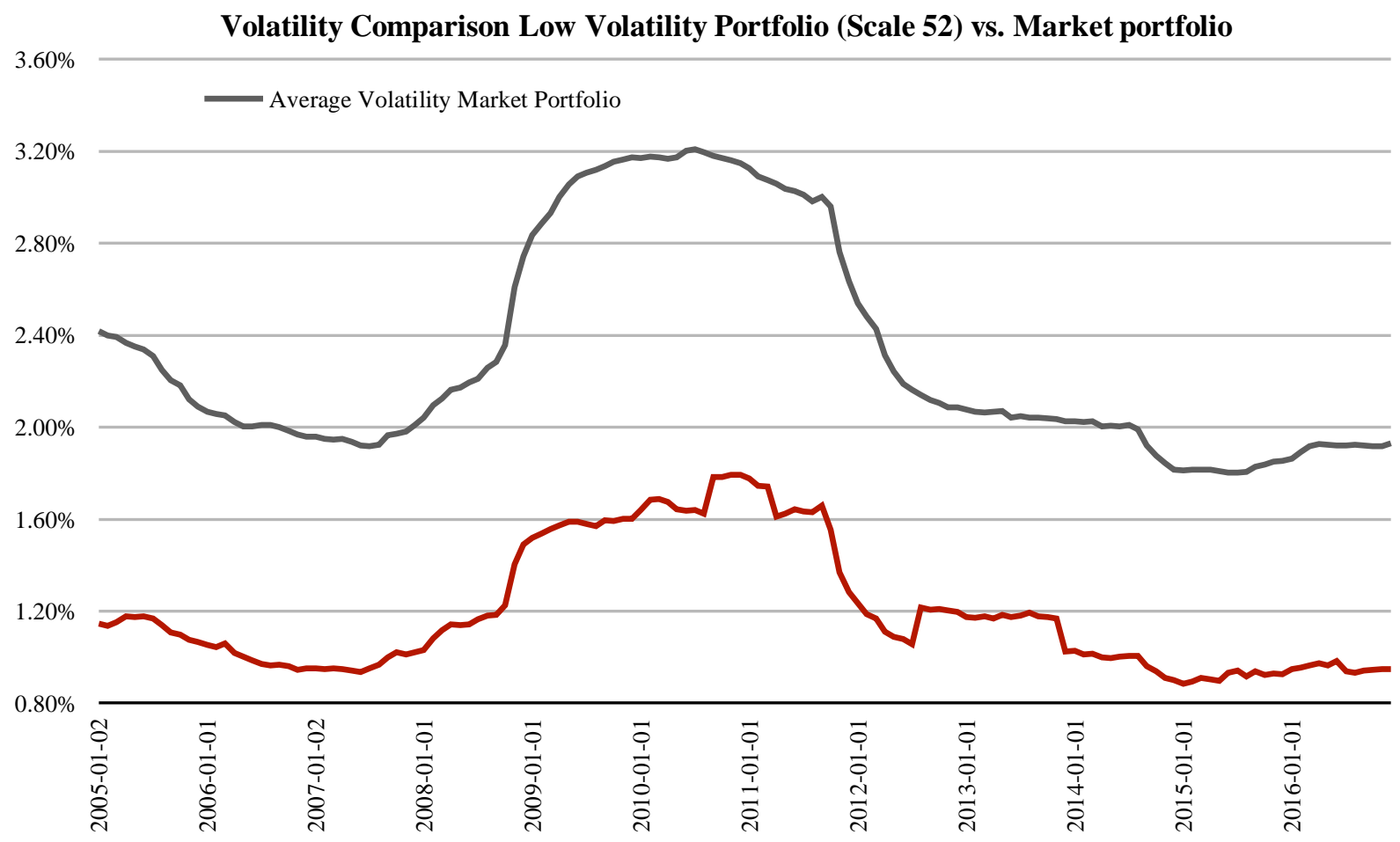

Figure 7. Volatility Comparison: Low Volatility Portfolio (Scale 52) vs. Market Portfolio 


\section{Hurst Exponent Comparison Low Volatility Portfolio (Scale 52) vs. Market portfolio}

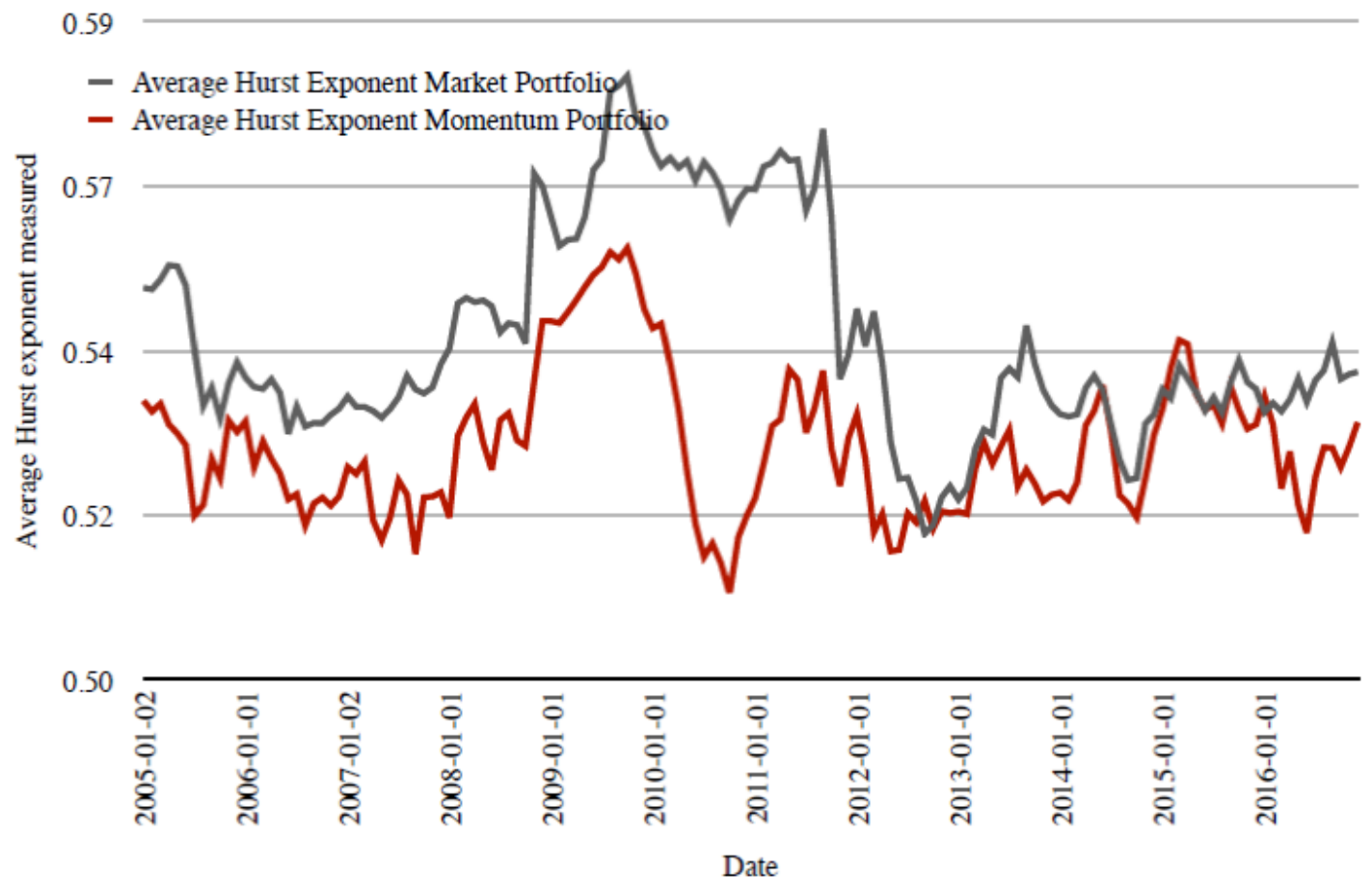

Figure 8. Hurst Exponent Comparison: Low Volatility Portfolio (Scale 52) vs. Market Portfolio

Average Scale Visible in Low Volatility Portfolio (Scale 52)

100

- Average Scale Visible

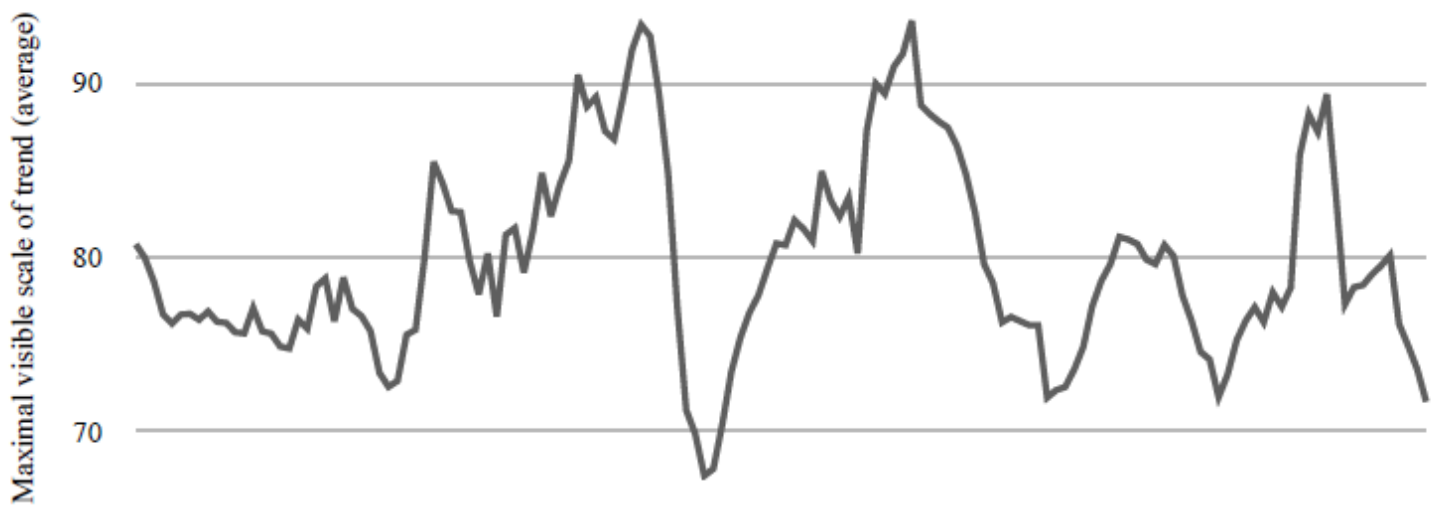

60

\begin{tabular}{|c|c|c|c|c|c|c|c|c|c|c|c|}
\hline & 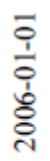 & $\begin{array}{l}\text { ô } \\
\frac{1}{0} \\
\stackrel{1}{0} \\
\stackrel{0}{0}\end{array}$ & $\begin{array}{l}\overline{0} \\
\dot{1} \\
\\
\dot{0} \\
\stackrel{\circ}{0} \\
\end{array}$ & 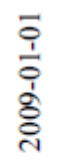 & $\begin{array}{l}\overline{0} \\
\frac{1}{0} \\
\text { d } \\
\text { o } \\
\text { d }\end{array}$ & $\begin{array}{l}\bar{o} \\
\frac{i}{0} \\
\stackrel{i}{\bar{i}} \\
\end{array}$ & $\begin{array}{l}\overline{0} \\
\stackrel{1}{0} \\
\grave{1} \\
\stackrel{\sim}{0}\end{array}$ & 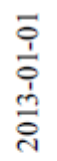 & 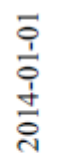 & $\begin{array}{l}\overline{0} \\
\frac{1}{0} \\
\dot{n} \\
\bar{n} \\
\text { N }\end{array}$ & $\begin{array}{l}\overline{0} \\
\frac{1}{0} \\
\dot{0} \\
\dot{0}\end{array}$ \\
\hline
\end{tabular}

Figure 9. Average Scale Visible in the Low Volatility Portfolio (replicated using trends at Scale 52) 
According to Figures 7,8 and 9 we draw the conclusion that low volatility strategies require trending, although trend scales used are significantly higher compared to momentum.

\section{Conclusion}

In the paper, we specify the terms of momentum and low volatility and demonstrate that lognormal trend characteristics constitute an underlying driving force.

\subsection{What Is Momentum?}

Momentum strategies assume selecting assets with sharp upward movements (with high drift and high volatility) at low scales to exploit trend continuation. As shown in Berghorn (2015), there is a relationship between trend drift and trend size. In other words, a trend that is visible on a specific wavelet scale requires either long or sharp price movements. Sharp price movements as exploited by momentum strategies are typically shorter movements. Based on the assumption of lognormality of underlying trend sizes and given that trends visible at higher scales are included in these distributions, one can easily conclude that momentum strategies select assets for which the probability of trend continuation is statistically higher.

\subsection{What Is Low Volatility?}

Similar to momentum, low volatility strategies assume selecting trending assets with low volatility. However, these assets are characterized by much higher wavelet scales, resulting in more robust and longer movements. Measuring low volatility can be regarded as an indirect measure. Since downward trends inhibit structurally higher volatility compared to upward trends a ranking criterion such as low volatility entails a structurally higher chance of selecting an upward trend (see Appendix D).

As momentum as well as low volatility strategies are indirectly based on the trend model, it becomes clear that these strategies represent two sides of the same medal. Both require the trending of assets, which directly violates the independence claim of the EMH.

\subsection{Summary and Final Comments}

In our experiments, we applied a wavelet-based trend model that follows Mandelbrot's original sketch as shown in Mandelbrot (2001). In Mandelbrot's view, such a model would provide a better description of data than Fractional Brownian Motions do. This paper shows that trends and the persistency of returns are closely related. The former reflects a non-stationary view of the data whereas the latter offers a stationary view.

Regarding characteristics of underlying stock market data, almost every asset used in our study exhibits a Hurst exponent higher than 0.5, which is a measure of persistency of returns. In our view, Mandelbrot and Van Ness (1968) incorrectly related this to a so-called 'long-term memory' effect. In our examples (as motivated by the experiments conducted by Lo (1991)) we are able to show that Hurst exponents measure characteristics of trends instead.

When one accepts the underlying assumption that the wavelet-based trend model offers a useful description of data because it reflects lognormal trend characteristics, the inner structure of well-known anomalies such as momentum and low volatility becomes clear. Both are very attractive from a mathematical point of view, as they directly violate the weak form of the EMH. Our Hurst exponent-based momentum strategy refers to inefficient markets (with the majority of assets having a Hurst exponent of above 0.5) and at the same time turns an investment scheme into a (theoretically) profitable strategy.

As we show in section 4.4, the Hurst exponent significantly improves low volatility strategies by over 50\% to $137 \%$ on a risk-adjusted return basis.

\section{Acknowledgements}

We would like to thank Heinz-Otto Peitgen and Marcel van Leeuwen (DPWT Deutsche Wertpapiertreuhand GmbH, Herzogenaurach, Germany) for their ongoing support and comments. We would also like to thank the Sparkasse Bremen AG for their partnership and for providing an open environment for fostering innovations in finance. We would also like to thank Prof. Dr. Matija Denise Mayer-Fiedrich for offering continuous support and scientific input.

\section{References}

Asness, C. S., \& Moskowitz, T. J., \& Pedersen, L. (2013). Value and Momentum Everywhere. Journal of Finance, 68(3), 929-986.

Bandarchuk, P., \& Hilscher, J. (2012). Sources of momentum profits: Evidence on the irrelevance of characteristics. Review of Finance, 17(2), 809-845. 
Berghorn, W. (2015). Trend Momentum. Quantitative Finance, 15(2), 261-284. https://doi.org/10.1080/14697688.2014.941912

Berghorn, W., \& Otto, S. (2017a). Mandelbrot Market-Model and Momentum. International Journal of Financial Research, 8(3). https://doi.org/10.5430/ijfr.v8n3p1

Berghorn, W., \& Otto, S. (2017b). Momentum: An Economic View. International Journal of Financial Research, 8(3), https://doi.org/10.5430/ijfr.v8n3p142

Black, F., \& Jensen, M., \& Scholes, M. S. (1972). The Capital Asset Pricing Model: Some Empirical Findings. In M. Jensen (Ed.), Studies in the Theory of Capital Markets (pp. 79-124), Praeger Publishers, New York.

Blitz, D., Hanauer, M. X., Vidojevic, M., \& van Vliet, P. (2016). Five Concerns with the Five-Factor Model. Retrieved from https://ssrn.com/abstract $=2862317$

Brenner, R. \& Maier-Paape, S. (2016). Survey on Log-Normally Distributed Market-Technical Trend Data. Risks, 4(20). Retrieved from https://www.mdpi.com/2227-9091/4/3/20

Carhart, M. M. (1997). On persistence in mutual fund performance. Journal of Finance, 52(1), 57-82.

Chan, L. K. C., Jegadeesh, N., \& Lakonishok, J. (1996). Momentum Strategies. Journal of Finance, 51(5), 1681-1713.

Cooper, M. J., Gutierrez, R. C., \& Hameed, A. (2004). Market states and momentum. Journal of Finance, 59(3), 1345-1365.

Cullen, A. C., \& Frey, H. C. (1999). Probabilistic techniques in exposure assessment. Springer US.

Daniel, K., \& Moskowitz, T. J. (2016). Momentum crashes. Journal of Financial Economics, 122(2), 221-247. https://doi.org/10.1016/j.jfineco.2015.12.002

DeBondt, W. F. M., \& Thaler, R. H. (1987). Further evidence on investor overreaction and stock market seasonality. Journal of Finance, 42(3), 557-581.

Fama, E. F. (1970). Efficient Capital Markets: A Review of Theory and Empirical Work. Journal of Finance, 25(2), 383-417.

Fama, E. F., \& French, K. R. (1992). The cross-section of expected stock returns, Journal of Finance, 47(2), 427-465.

Fama, E. F., \& French, K. R. (1996). Multifactor explanations of asset pricing anomalies. Journal of Finance, 51(1), 55-84.

Fama, E. F., \& French, K. R. (2008). Dissecting Anomalies, Journal of Finance, 63(4), 1653-1678. https://doi.org/10.1111/j.1540-6261.2008.01371.x

Frazzini, A., \& Pedersen, L. H. (2014). Betting against beta. Journal of Financial Economics, 111(1), 1-25. https://doi.org/10.1016/j.jfineco.2013.10.005

Friend, I., \& Blume, M. (1970). Measurement of Portfolio Performance Under Uncertainty. The American Economic Review, 60(4), 561-575. Retrieved from http://www.jstor.org/stable/1818402

George, T. J., \& Hwang, C.-Y. (2004). The 52-week high and momentum investing. Journal of Finance, 59(5), 2145-2176.

Grinblatt, M., Titman, S., \& Wermers, R. R. (1994). Momentum Investment Strategies, Portfolio Performance, and Herding: A Study of Mutual Fund Behavior. Retrieved from http://ssrn.com/abstract=5686

Grundy, B. D., \& Martin, J. S. (2001). Understanding the Nature of the Risks and the Source of the Rewards to Momentum Investing. Review of Financial Studies, 14(1), 29-78.

Haugen, R., \& Heins, A. (1975). Risk and the Rate of Return on Financial Assets: Some Old Wine in New Bottles. Journal of Financial and Quantitative Analysis, 10(5), 775-784.

Hong, H., Lim, T., \& Stein, J. C. (2000). Bad News Travels Slowly: Size, Analyst Coverage, and the Profitability of Momentum Strategies. Journal of Finance, 55(1), 265-295.

Hooke, R., \& Jeeves, T. A. (1961). Direct search solution of numerical and statistical problems. Journal of the ACM, 8(2), 212-229. Retrieved from https://dl.acm.org/doi/10.1145/321062.321069

Jacobs, H., \& Weber, M. (2013). Losing sight of the trees for the forest? Attention allocation and anomalies. 
https://doi.org/10.2139/ssrn.2023539

Jegadeesh, N., \& Titman, S. (2001). Profitability of Momentum Strategies: An Evaluation of Alternative Explanations. Journal of Finance, 56(2), 699-720.

Jegadeesh, N. (1990). Evidence of predictable behavior of security returns. Journal of Finance, 45(3), 881-898.

Jegadeesh, N., \& Titman, S. (1993). Returns to buying winners and selling losers: Implications for stock market efficiency. Journal of Finance, 48(1), 65-91.

Kahneman, D. (2011). Thinking Fast and Slow. Allen Lane.

Lee, C. M. C., \& Swaminathan, B. (2000). Price Momentum and Trading Volume. Journal of Finance, 55(5), 2017-2069.

Liew, J. K.-S., \& Vassalou, M. (1999). Can Book-to-Market, Size, and Momentum Be Risk Factors That Predict Economic Growth?. https://doi.org/10.2139/ssrn.159293

Lo, A. W. (1991). Long-Term Memory in Stock Market Prices. Econometrica, 59(5), 1279-1313, Retrieved from www.jstor.org/stable/2938368

Lo, A. W., \& McKinlay, A.C. (1998). Stock market prices do not follow random walks: evidence from a simple specification test. Review of Financial Studies, 1(1), 41-66.

Louis, A. K., Maaß, P., \& Rieder, A. (1994). Wavelets. B.G. Teubner, Stuttgart.

Maass, P., Koehler, T., Kalden, J., Costa, R., Parlitz, U., Merkwirth, C., \& Wichard, J. (2003). Mathematical methods for forecasting bank transaction data. Mathematical methods for time series analysis and digital image processing, Preprint 24.

Mandelbrot, B. B. (2001). Scaling in financial prices. Quantitative Finance, 1(6), 427-440. https://doi.org/10.1088/1469-7688/1/6/306

Mandelbrot, B. B., \& Van Ness, J. W. (1968). Fractional Brownian Motions, Fractional Noises and Applications. Society for Industrial and Applied Mathematics Review, 10(4), 422-437.

Moskowitz, T. J., \& Grinblatt, M. (1999). Do Industries Explain Momentum?. Journal of Finance, 54(4), 1249-1290.

Moskowitz, T. J., Ooi, Y. H., \& Pedersen, L. H. (2010). Time series momentum. Journal of Financial Economics, 104(2), 228-250. https://doi.org/10.1016/j.jfineco.2011.11.003

Novy-Marx, R. (2012). Is momentum really momentum?. Journal of Financial Economics, 103(3), 429-453.

Okunev, J., \& White, D. (2003). Do momentum-based strategies still work in foreign currency markets?. Journal of Financial and Quantitative Analysis, 38(2), 425-447.

Rouwenhorst, K. G. (1998). International momentum strategies. Journal of Finance, 53(1), 267-284. https://doi.org/10.1111/0022-1082.95722

Schiereck, D., De Bondt, W., \& Weber, M. (1999). Contrarian and momentum strategies in Germany. Financial Analysts Journal, 55, 104-116.

Stevenson, R. A., \& Bear, R. M. (1970). Commodity Futures: Trends or Random Walks. Journal of Finance, 25(1), 65-81.

Taylor, S. J. (1962). Tests of the Random Walk Hypothesis Against a Price-Trend Hypothesis. Journal of Finance and Quantitative Analysis, 17(1), 37-61.

Thaler, R. H. (2015). Misbehaving: The making of behavioral economics. New York, W W Norton \& Co.

\section{Notes}

Note 1. Please note that we avoid any mathematical notations in order to enhance readability. If we talk about trend drift or trend volatility we refer to estimates that are derived from the relevant trend segment. Please refer to Berghorn and Otto (2017a) for a more mathematical definition.

Note 2. The optimization problem is to find a scale so that the resulting momentum scheme based on the wavelet trend decomposition is 'close' to the classical momentum scheme. This is the reason why we implemented a pattern search algorithm similar to Hooke and Jeeves (1961). 
Note 3. For mathematical definitions, we refer to Berghorn and Otto (2017a).

Note 4. This experiment also highlights that mean reversion strategies and momentum can coexist. In the absence of trends, momentum does not exist. The remaining market can be viewed as a mean reversion market (the majority of assets have Hurst exponents of less than 0.5) plus some noise.

\section{Appendix A}

\section{Risk and Return Characteristics Used}

Throughout this paper, we measure different characteristics and compare them with the market proxy. The first three rows of table 1, table 3, table 4, table 5 and table 6 show the annualized return, the annualized excess return compared to the market proxy, and the annualized volatility. Latter is based on the daily volatility estimated from the standard deviation of daily logreturns. This volatility estimate is then scaled with the square root of 261 (trading days) to obtain an annual value.

Risk-adjusted returns are calculated by dividing the daily drift with the daily volatility. Maximal drawdowns refer to the maximal loss encountered in the price series. We also apply a linear model $y=\boldsymbol{\alpha}+\boldsymbol{\beta} x_{\text {to describe logreturns }}$ of the classical momentum strategy, whereas alpha $(\boldsymbol{\alpha})$ and beta $(\boldsymbol{\beta})$ are estimated by using OLS-approaches. We also provide the determination coefficient, $\mathrm{R} 2$, which corresponds to the squared correlation between $\mathrm{x}$ and $\mathrm{y}$.

\section{Appendix B}

\section{Hurst Exponents}

Figure 10 shows the corresponding Hurst exponent minus 0.5 for each asset of the Bloomberg World Index Ex China. We filter out all assets with less than 1 year (261 days) of price records. In total $90.63 \%$ of the analysed 3,619 assets exhibit Hurst exponents higher than 0.5.

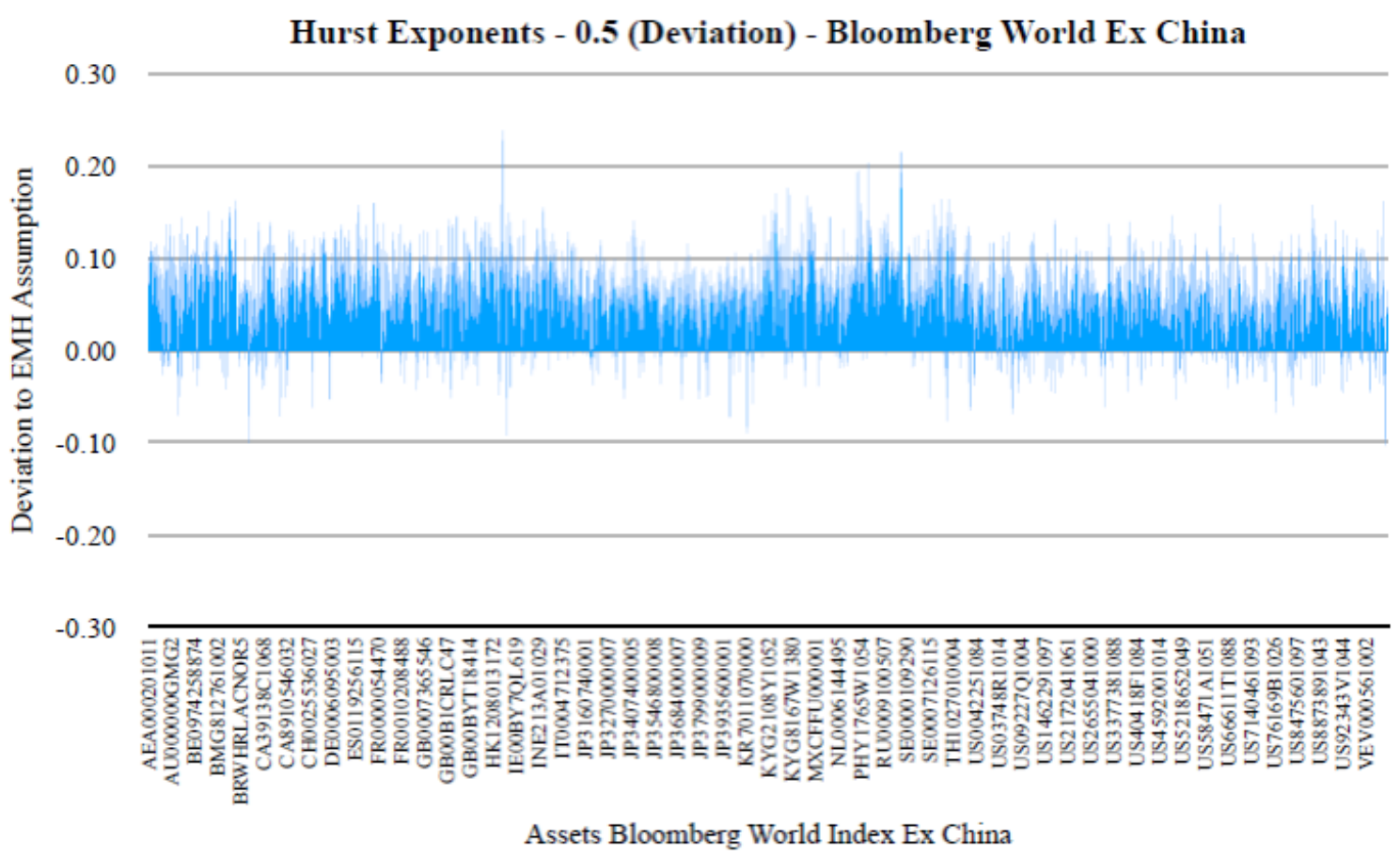

Figure 10. Hurst Exponents - 0.5: Bloomberg World Index Ex China 


\section{Appendix C}

\section{Hurst Exponents after detrending}

Figure 11 shows the Hurst exponent for each asset of the Bloomberg World Index Ex China minus 0.5 based on a detrending algorithm. For each asset, we calculate the corresponding wavelet trend model. We then calculate the logreturn of the original time series and subtract the logreturn of the linear trend model. We again filter out all assets with less than 1 year (261 days) of price records. The majority of assets provide Hurst exponents of less than 0.5 . Only $7.61 \%$ of the assets maintain a Hurst exponent of greater than 0.5 . In the absence of trends at a scale of 19 , the detrended cohort has an average Hurst exponent of 0.42 , showing anti-persistency in logreturns.

\section{Hurst Exponents - 0.5 (Deviation) - Bloomberg World Ex China (Detrended Scale}

\section{9)}

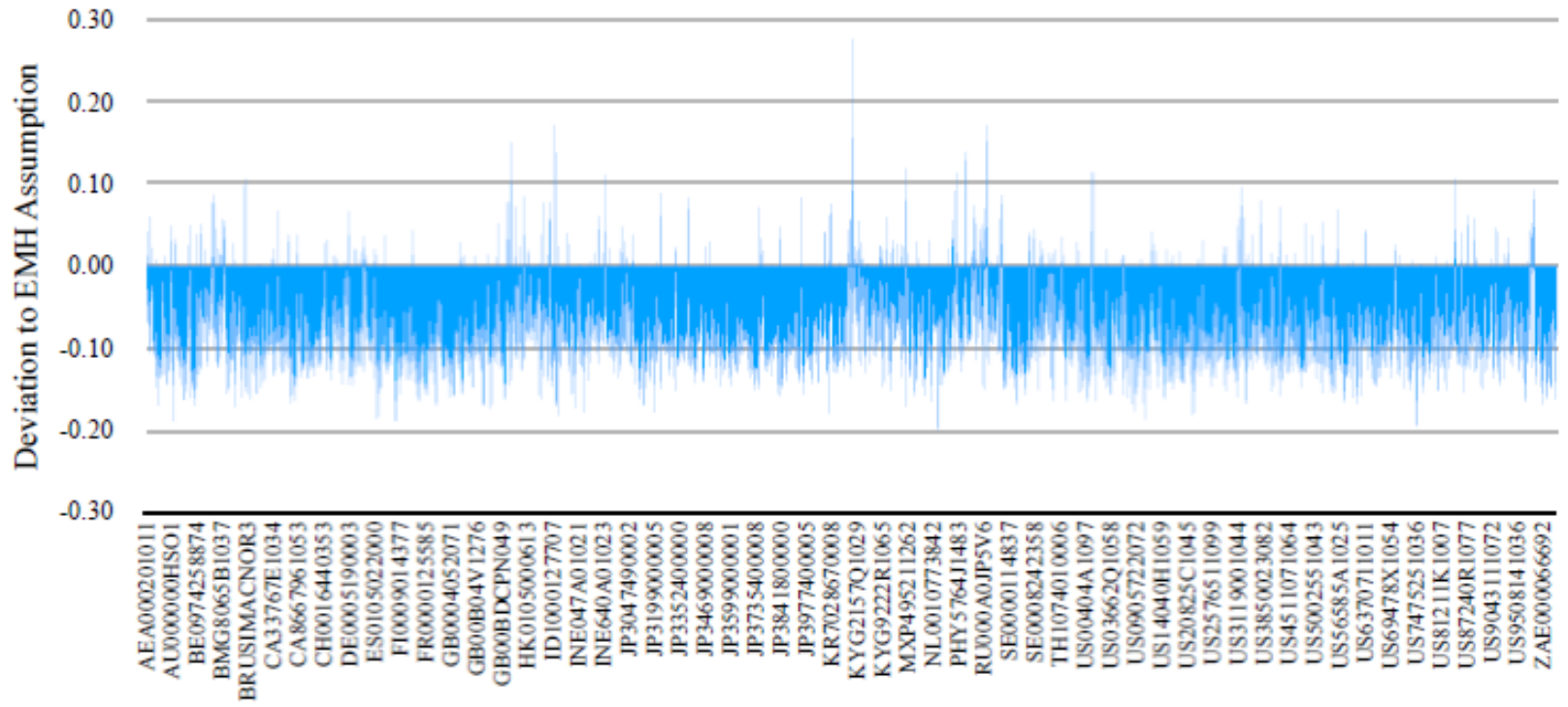

Assets Bloomberg World Index Ex China

Figure 11. Hurst Exponents - 0.5: Bloomberg World Index Ex China (Detrended Scale 19) 


\section{Appendix D}

\section{Number of Assets with Upward Trends in a Low Volatility Portfolio}

In figure 12 we use the matched low volatility strategy of the wavelet-based trend model to determine that more than $67 \%$ of the assets exhibit upward trends (at scale 52 and higher).

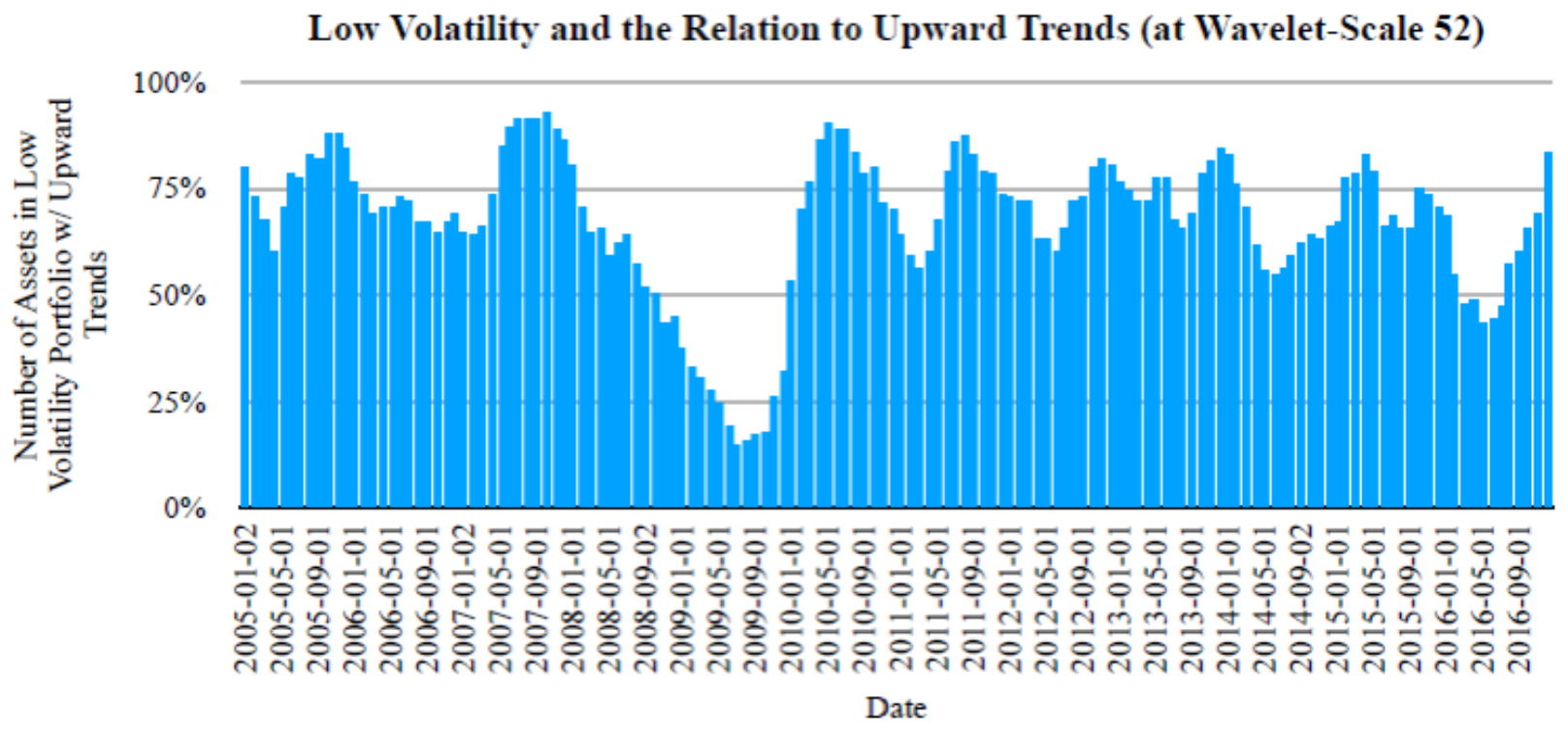

Figure 12. Number of Assets with Upward Trends in a Low Volatility Factor Portfolio (Monthly) at Wavelet-Scale 52

\section{Copyrights}

Copyright for this article is retained by the author(s), with first publication rights granted to the journal.

This is an open-access article distributed under the terms and conditions of the Creative Commons Attribution license (http://creativecommons.org/licenses/by/4.0/). 